\title{
Idebenone Prevents Human Optic Nerve Head Astrocytes From Oxidative Stress, Apoptosis, and Senescence by Stabilizing BAX/BCl-2 Ratio
}

\author{
Marcus Kernt, MD, Nicole Arend, MD, Alexandra Buerger, MD, Thomas Mann, MD, \\ Christos Haritoglou, MD, Michael W. Ulbig, MD, Anselm Kampik, MD, and Christoph Hirneiss, MD
}

\begin{abstract}
Purpose: Oxidative stress plays an important role in the pathogenesis of several neurodegenerative diseases including glaucoma. Astrocytes are supposed to play a role in glaucoma pathogenesis. This study investigates the antiapoptotic and cytoprotective effects of idebenone on optic nerve head astrocytes (ONHA) under oxidative stress
\end{abstract}

Methods: ONHA were treated with 1 to $150 \mu \mathrm{M}$ idebenone. Cell viability (MTT assay and live-dead assay), induction of intracellular reactive oxygen species, senescence-associated $\beta$-galactosidase activity were investigated. In addition, apoptosis (detection of histone-associated DNA fragmentation), and expression of BAX and $\mathrm{Bcl}-2$, and their mRNA were determined after 48 hours and after hydrogen peroxide $\left(\mathrm{H}_{2} \mathrm{O}_{2}\right)$ treatment.

Results: Idebenone concentrations from 1 to $50 \mu \mathrm{M}$ showed no effects on ONHA viability. Pretreatment with $10 \mu \mathrm{M}$ idebenone led to an increase in viability of ONHA after $\mathrm{H}_{2} \mathrm{O}_{2}$ treatment. In addition, idebenone pretreatment significantly attenuated the increase of histone-associated DNA fragmentation, induction of senescence-associated $\beta$-galactosidase, and intracellular reactive oxygen species after treatment with $\mathrm{H}_{2} \mathrm{O}_{2}$. When ONHA cells were treated with idebenone and $\mathrm{H}_{2} \mathrm{O}_{2}$, real-time polymerase chain reaction and Western blot analysis yielded an increased expression of Bcl-2 and a decrease of BAX compared with those cells that were treated with $\mathrm{H}_{2} \mathrm{O}_{2}$ only.

Conclusions: Idebenone reduced senescence, oxidative stress, and apoptotic cell death in cultured ONHA in vitro. Our results suggest that idebenone may help to protect ONHA in vivo, and therefore might be helpful in preventing the progression of glaucomatous degeneration.

Key Words: glaucoma, optic nerve head, astrocytes, senescence, oxidative stress, apoptosis, antioxidants, idebenone, coenzyme Q10

(J Glaucoma 2013;22:404-412)

G laucoma is a distinctive group of progressive neurodegenerative diseases affecting the optic nerve. It is characterized by accelerated death of retinal ganglion cells (RGCs) and circumjacent glial cells. Consequently, with the progression of glaucoma, an irretrievable loss of visual field and eventual blindness occurs. ${ }^{1}$ Currently, an estimated 60 million people have glaucoma, and it is the second leading

Received for publication December 11, 2010; accepted January 9, 2012. From the Department of Ophthalmology, Ludwig Maximilian University, Munich, Germany.

Disclosure: The authors declare no conflict of interest.

Reprints: Marcus Kernt, MD, Department of Ophthalmology, Ludwig Maximilian University, Mathilden St 8, 80336 Munich, Germany (e-mail: marcus.kernt@med.uni-muenchen.de).

Copyright (C) 2013 by Lippincott Williams \& Wilkins

DOI: 10.1097/IJG.0b013e31824caf90 cause of blindness worldwide. ${ }^{1}$ The number of patients affected by glaucoma is estimated to increase to 80 million by $2020{ }^{1}$

To date, lowering intraocular pressure (IOP) is the only treatment proven to decrease the development ${ }^{2}$ and progression $^{3}$ of glaucomatous optic nerve damage. Beside IOP, there are several risk factors for glaucoma progression including age, central corneal thickness, exfoliation, or lower ocular systolic perfusion pressure. ${ }^{4,5}$ Lowering IOP alone does not halt the progression of the disease in all patients, and additional therapeutic approaches for protecting the optic nerve are sought. ${ }^{4,5}$

Looking at the cellular level of glaucoma's pathogenesis, there is increasing evidence that apoptosis is an important mechanism of neuronal cell (RGCs) death, as well as of supportive glial cells in glaucomatous neurodegeneration. Apoptotic cell death has been observed in both animal glaucoma models and human eyes with glaucoma. ${ }^{6-9}$

In the eye, astrocytes are present both in the inner retina as well as in the unmyelinated optic nerve head astrocytes (ONHA) and act as neuronal supportive cells by regulating ionic balance, metabolic supply, and structural support. ${ }^{10-12}$ Ocular astrocytes are thought to contribute to both homeostatic functions of the RGCs and optic nerve, as well as directly contributing to the pathophysiology resulting in damage to both ganglion cells and optic nerve. ${ }^{10-13}$

Astrocytes, and glial cells in general, are the interface between neurons and vasculature and thus are strategic key regulators of the nutrition and metabolism of RGCs and the optic nerve. ${ }^{14}$ In glaucoma the communication between RGCs and these supportive glial cells is strongly disturbed. $^{14,15}$ Glaucomatous neuropathology leads to a change of glial cell morphology and protein expression, a process referred to as glial activation (or reactive gliosis). ${ }^{16}$ Prelaminar ONHAs round up and migrate, abandoning their columnar organization. It was shown previously that the inhibition of reactive gliosis can attenuate the death of $\mathrm{RGCs}^{17}$; thus, providing proof of concept for pursuing other novel inhibitors of reactive gliosis as potential new treatment options for patients with glaucoma.

Oxidative stress is a prominent feature of aging and has been implicated as a relevant factor in the development of many diseases, including glaucoma. ${ }^{18-23}$ Moreover, oxidative stress can lead to apoptosis of both, RGCs themselves and supportive glial cells like ONHAs. The processes that lead to the development of oxidative stress may also contribute to neurodegeneration in glaucoma. ${ }^{24-26}$

Idebenone (2,3-dimethoxy-5-methyl-6-[10-hydroxydecyl]1,4-benzoquinone) is a benzoquinone derivative that is 
structurally related to ubiquinone (coenzyme Q10), a component of the respiratory chain. ${ }^{27}$ Although the precise mechanism of action of the drug is unknown, preclinical studies have suggested that idebenone may exert cytoprotective properties by acting as a scavenger of free radicals. ${ }^{27}$ Beneficial effects of idebenone have been demonstrated in the treatment of several neurodegenerative diseases in which glial tissue is involved in the pathogenesis, including the Leber hereditary optic neuropathy. ${ }^{28-33}$ Besides the antioxidant properties of idebenone, effects of the substance on expression of antiapoptotic proteins also have been described. ${ }^{34,35}$

Oxidative stress is a pathological condition in which the rate of reactive oxygen species (ROS) production exceeds the body's antioxidative capacity. In various neurodegenerative diseases, localization of tissue markers of oxidative stress to lesion areas has led to suggestions that oxidative injury contributes to the disease process. Astrocytes seem to be highly susceptible to oxidative stress, and astrocyte dysfunction is closely related to glaucomatous optic nerve damage. ${ }^{14,15,25,36}$

This study investigates the effects of idebenone on oxidative stress, cellular senescence, and apoptosis of primary human ONHA as a possible treatment option for diagnosed glaucoma patients.

\section{METHODS}

Idebenone was generously provided by Santhera Pharmaceuticals (Liestal, Switzerland). The compound was dissolved in dimethyl sulfoxide (DMSO; Sigma-Aldrich, St Louis, MO) and diluted with DMSO and the cell culture medium to the desired concentration with a final DMSO concentration of $0.1 \%(\mathrm{v} / \mathrm{v})$ for in vitro studies. DMSO was added to cultures at $0.1 \%(\mathrm{v} / \mathrm{v})$ as a solvent control.

\section{Ethics}

The methods of securing human tissue were humane, included proper consent and approval, complied with the Declaration of Helsinki, and were approved by the local ethics committee.

\section{Primary Human ONHA Culture}

Primary cell cultures of human lamina cribrosa astrocytes were obtained from the eye bank of the Ludwig Maximilian University (Munich, Germany). Monolayer cultures were established from eyes of 4 human donors (29, 41,52 , and $74 \mathrm{y}$ old, obtained 3 to $10 \mathrm{~h}$ postmortem) without any history of eye diseases. The eyes were prepared and grown as previously described. ${ }^{10-12}$ A 1:1 mixture of Dulbecco-modified Eagle medium (DMEM) and Ham F-12 medium was used for cell culture and passages 2 to 5 were used for our experiments.

\section{Cell Culture Treatment}

For tetrazolium dye-reduction assay (MTT; 3-[4,5dimethylthiazol-2-yl]-2,5-diphenyl tetrazolium bromide) and propidium iodide (PI)/Hoechst 33342 staining, ONHA were seeded in 6-well tissue culture plates and exposed to various idebenone concentrations $(1,5,7.5,10,15,20,40$, $50,75,100$, and $150 \mu \mathrm{M})$. To investigate the effects of idebenone on ONHA regarding RNA and protein expression, an idebenone concentration of $10 \mu \mathrm{M}$ was chosen.

For all other cell culture experiments, ONHA were seeded in the tissue culture plates and cultured upon confluence. For the last 48 hours, $10 \mu \mathrm{M}$ idebenone was added to the cell culture medium. Then ONHA were kept for 24 hours in serum-free conditions: after the cells were washed with phosphate-buffered saline (PBS), they were incubated for another 24 hours with idebenone $(10 \mu \mathrm{M})$ dissolved in serum-free DMEM/F12 medium.

To test the effects of idebenone under conditions of oxidative stress, ONHA were exposed to hydrogen peroxide $\left(\mathrm{H}_{2} \mathrm{O}_{2}\right)$. In unpublished prework of our laboratory several concentrations of $\mathrm{H}_{2} \mathrm{O}_{2}$ and times of treatment were tested and the concentration of $600 \mu \mathrm{M} \mathrm{H} \mathrm{H}_{2} \mathrm{O}_{2}$ and a 4-hour treatment was chosen in order to produce an adequate degree of cell injury in untreated ONHA. To investigate idebenones effect on $\mathrm{H}_{2} \mathrm{O}_{2}$-induced cellular damage, cells were treated as described above, but $600 \mu \mathrm{M} \mathrm{H}_{2} \mathrm{O}_{2}$ was added for the last 4 hours. Then the serum-free medium containing $\mathrm{H}_{2} \mathrm{O}_{2}$ and idebenone was removed by carefully rinsing the cells with serum-free medium 3 times. After another 24 hours of incubation with serum-free medium, MTT assay, PI, and Hoechst 33342 staining, quantitative detection of histone-associated DNA fragments in mononucleosomes and oligonucleosomes, CM-H2DCFDA staining, and senescence-associated $\beta$-galactosidase (SA $\beta$ Gal) staining were investigated. In addition, real-time polymerase chain reaction (RT-PCR) analysis and Western blotting was performed.

\section{MTT Assay}

The MTT assay is a well-established test for measuring metabolic activity of cells, and it can occasionally be used as indirect measure of cell viability. To determine metabolic activity of ONHA, MTT assay was performed as described in the literature by Mosmann, with some modifications. ${ }^{37-39}$ The medium was removed, cells were washed with PBS, and $1000 \mu \mathrm{L} /$ well MTT solution $(1.5 \mathrm{~mL}$ MTT stock, $2 \mathrm{mg} / \mathrm{mL}$ in PBS, plus $28.5 \mathrm{~mL}$ DMEM) was added. ONHA were incubated at $37^{\circ} \mathrm{C}$ for 1 hour. The formazan crystals that formed were dissolved by the addition of DMSO $(1000 \mu \mathrm{L} /$ well). Absorption was measured by a scanning multiwell spectrophotometer (Molecular Probes, Garching, Germany) at $550 \mathrm{~nm}$. Results are expressed as the mean percentage of control proliferation. Experiments were performed in triplicate and repeated 3 times. Untreated ONHA of the same passage served as the control. Values of each sample were normalized to a "blank" containing DMSO only.

\section{PI and Hoechst 33342 Staining}

Confluent ONHA were prepared and treated as described above. Cell viability was quantified by PI (SigmaAldrich) and Hoechst 33342 (Intergen, Purchase, NY) double staining. Confluent cultures of ONHA growing on coverslips were exposed to the same concentrations of idebenone as in the MTT assay. Then, cells were washed in PBS and incubated with $2.0 \mu \mathrm{g} / \mathrm{mL}$ PI and $1.0 \mu \mathrm{g} / \mathrm{mL}$ Hoechst 33342 resolved in PBS for 20 minutes at $37^{\circ} \mathrm{C}$. Subsequently, stains were removed, cells were washed with PBS, and then analyzed with an epifluorescence microscope (Aristoplan; Leitz, Wetzlar, Germany). The labeled nuclei were then counted in fluorescence photomicrographs, and the percentage of PI-labeled nuclei was counted in 3 to 5 documented representative fields per well. The data are based on counts in 3 experiments performed in duplicate wells, with untreated ONHA of the same passage serving as the control. 


\section{Detection of Histone-associated DNA Fragments in Mononucleosomes and Oligonucleosomes}

Apoptosis is characterized by membrane blebbing, condensation of cytoplasm, and the activation of endogenous endonucleases. This leads to internucleosomal cleavage of DNA and the generation of mononucleosomes and oligonucleosomes that are tightly complexed with histones. To quantify apoptosis in ONHA, detection of histoneassociated DNA fragments in mononucleosomes and oligonucleosomes was performed by enzyme-linked immune sorbent assay (ELISA). ONHA were treated with idebenone $(10 \mu \mathrm{M})$ as described above. Cells were then collected from culture plates and subjected to a cell death detection ELISA (Roche Applied Science, Indianapolis, IN) according to the manufacturer's recommendations.

\section{Detection of SA $\beta$-Gal Activity}

The proportion of ONHA positive for SA $\beta$-Gal activity was determined as described by Dimri et al. ${ }^{40}$ Briefly, treated ONHA were washed twice with PBS and fixed with $2 \%$ formaldehyde and $0.2 \%$ glutaraldehyde in PBS ( $\mathrm{pH}$ 6.0) at room temperature for 4 minutes. The cells were then washed twice with PBS and incubated for 8 hours at $37^{\circ} \mathrm{C}$ with freshly prepared SA $\beta$-Gal staining solution [ $1 \mathrm{mg} / \mathrm{mL}$ 5-bromo-4-chloro-3-indoyl- $\beta$-D-galactopyranoside, $40 \mathrm{mM}$ citric acid-sodium phosphate solution $(\mathrm{pH}$ 6.0), $5 \mathrm{mM}$ potassium ferrocyanide, $5 \mathrm{mM}$ potassium ferricyanide, $150 \mathrm{mM} \mathrm{NaCl}$, and $2 \mathrm{mM} \mathrm{MgCl}$ diluted in PBS] in darkness. Subsequently, SA $\beta$-Gal staining solution was removed, cells were washed with PBS and cells were then examined for the development of blue color and photographed at low magnification $(\times 200)$ using a light microscope. The results are expressed as mean average percentage $\pm \mathrm{SD}$ of 12 experiments using ONHA cultures from 4 donors.

\section{Detection of Intracellular ROS}

Intracellular ROS production was detected by the method described by Nishikawa and colleagues ${ }^{39,41,42}$ ONHA cultured in presence of $10 \mu \mathrm{M}$ idebenone were treated with $600 \mu \mathrm{M} \mathrm{H} \mathrm{H}_{2} \mathrm{O}_{2}$ as described above. Then the cells were supplemented with 5-(and-6)-chloromethyl-2',7'dichlorodihydro-fluorescein diacetate acetyl ester (CMH2DCFDA; Molecular Probes, Eugene, OR) dissolved in Krebs-Ringer bicarbonate buffer $(135 \mathrm{mM} \mathrm{NaCl}, 3.6 \mathrm{mM}$ $\mathrm{KCl}, 10 \mathrm{mM}$ HEPES, $5 \mathrm{mM} \mathrm{NaHCO}, 0.5 \mathrm{mM} \mathrm{NaH} \mathrm{PO}_{4}$, $0.5 \mathrm{mM} \mathrm{MgCl}_{2}, \mathrm{pH} 7.4$ ) to a final concentration of $10 \mu \mathrm{M}$ CM-H2DCFDA for 30 minutes, incubated with DMEM/ F12 medium for 2 hours. Subsequently, CM-H2DCFDA staining solution was removed, cells were washed with PBS and analyzed under an epifluorescence microscope (Aristoplan; Leitz).

\section{RNA Isolation and RT-PCR}

RNA isolation by using the guanidium thiocyanatephenol-chloroform extraction method and RT-PCR using the LightCycler System (Roche Diagnostics, Mannheim, Germany) was performed as described previously. ${ }^{11,43}$ Quantitation of Bcl-2 and BAX mRNA was performed with specific primers (Table 1). Primers and probes were selected by the ProbeFinder version 2.04 software. All primers and probes were designed to cross intron-exon boundaries in order to avoid amplification of genomic DNA. All PCR products were sequenced to ensure product validity. To normalize for differences in the amount of total RNA added to each reaction, $18 \mathrm{~S}$ rRNA was simultaneously processed in the same sample as an internal control. The levels of Bcl-2 and BAX mRNA were determined as the relative ratio, which was calculated by dividing the level of Bcl-2 or BAX mRNA by the level of the 18S rRNA housekeeping gene in the same samples. Ratios are expressed in a decimal format. All experiments were performed at least in triplicate and repeated 3 times.

\section{Protein Extraction and Western Blot Analysis}

ONHA grown on 35-mm tissue culture plates were washed twice with ice-cold PBS, collected, and lysed in RIPA cell lysis buffer. After centrifugation for 30 minutes at $19,000 \mathrm{~g}$ in a microfuge (5810R; Eppendorf, Hamburg, Germany) in the cold, the supernatant was transferred to fresh tubes and stored at $-70^{\circ} \mathrm{C}$ for future use. The protein content was measured by the bicinchoninic acid protein assay (Pierce, Rockford, IL). Denatured proteins (1.2 mg) were separated by electrophoresis under reducing conditions using a 5\% sodium dodecyl sulfate-polyacrylamide stacking gel and a $12 \%$ sodium dodecyl sulfate-polyacrylamide separating gel, transferred with semidry blotting onto a polyvinyl difluoride membrane (Roche), and probed with a mouse anti-Bcl-2-antibody or a mouse anti-BAXantibody as described previously. ${ }^{39,43}$ Chemiluminescence was detected with an imager (LAS-1000; RayTest) and generated light units as described previously. ${ }^{38,43}$ Exposure times ranged from 1 to 10 minutes. Quantification was performed using AIDA software (RayTest). All experiments were performed at least in triplicate in ONHA cultures from 3 donors. An even protein load in each lane was confirmed by staining of the polyvinyl difluoride membranes with Coomassie brilliant blue after the blotting and detection procedure.

\section{Statistical Analysis}

Data were analyzed using SPSS 13.0 for Windows (SPSS Inc., Chicago, IL). Statistical comparisons among the different concentrations of idebenone (each repeated 3 times and measured in triplicate) was performed with the Mann-Whitney test. For the MTT assay quantitative results are presented as mean (SD) units of absorbance. Ten

TABLE 1. Primers Used for RT-PCR

\begin{tabular}{lccccc}
\hline Target & Length & Position & AT $\left({ }^{\circ} \mathbf{C}\right)$ & \% GC & Sequence \\
\hline Bcl-2 & 19 & $3465-3483$ & 60 & 58 & agaggtcacgggggctaat \\
& 20 & $3505-3524$ & 60 & 50 & ccaggtaacaaaaccccaca \\
BAX & 18 & $526-543$ & 59 & 61 & caagaccagggtggttgg \\
& 18 & $592-609$ & 59 & 56 & cactcccgccacaaagat \\
\hline
\end{tabular}

RT-PCR indicates real-time polymerase chain reaction. 
individual samples per group were measured in triplicate and comparisons were performed using the Mann-Whitney test. For RT-PCR, the results are presented as mean ratios (SD) of the investigated mRNA and 18S rRNA. Again, Mann-Whitney testing was applied, and all experiments were performed in triplicate and repeated 3 times. For all statistical tests, $P<0.05$ was considered significant.

\section{RESULTS}

\section{MTT Assay, and PI/Hoechst 33342 Staining}

We analyzed the dose-dependent toxic effects of idebenone at concentrations of 1, 5, 7.5, 10, 15, 20, 40, 50, 75, 100 , and $150 \mu \mathrm{M}$ by MTT assay and PI/Hoechst 33342 staining.

\section{MTT Assay}

Idebenone showed no significant effects on metabolic activity of ONHA cell cultures (48-h exposure) at concentrations between 1 and $50 \mu \mathrm{M}$ (Fig. 1). No significant decrease was detected in cellular viability of ONHA compared with the controls at concentrations up to $50 \mu \mathrm{M}$. Idebenone concentrations of $75 \mu \mathrm{M}$ and higher for primary ONHA led to a dose-dependent reduction of metabolic activity of cells. When ONHA cells were also treated with $\mathrm{H}_{2} \mathrm{O}_{2}$, those cells pretreated with idebenone concentrations of 7.5 to $20 \mu \mathrm{M}$ showed a significant increase in metabolic activity, with a peak at $10 \mu \mathrm{M}(P<0.001)$ compared with the control (Fig. 1).

\section{PI and Hoechst 33342 Staining}

The viability of primary ONHA was tested by labeling the nuclei of nonviable cells with PI 48 hours after treatment of the cells with idebenone and $\mathrm{H}_{2} \mathrm{O}_{2}$. Idebenone concentrations of 1 to $100 \mu \mathrm{M}$ did not show any significant effect on ONHA cell viability (Fig. 2). When primary ONHA were treated with an idebenone concentration of $10 \mu \mathrm{M}$ for 48 hours and additionally treated with $600 \mu \mathrm{M}$ $\mathrm{H}_{2} \mathrm{O}_{2}$ for 4 hours, idebenone concentrations of $10 \mu \mathrm{M}$ led to a significant increase in viability compared with the control, which was treated with $600 \mu \mathrm{M} \mathrm{H_{2 }} \mathrm{O}_{2}$ only (Fig. 2). By contrast, idebenone concentrations of $75 \mu \mathrm{M}$ and higher induced a marked reduction in the viability of ONHA cells in a dose-dependent manner after exposure to $600 \mu \mathrm{M} \mathrm{H}_{2} \mathrm{O}_{2}$ for 4 hours.

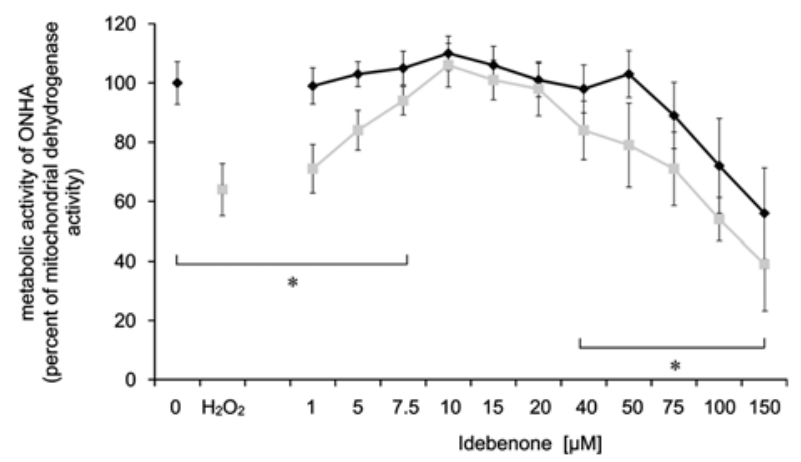

FIGURE 1. The viability of optic nerve head astrocytes (ONHA) after 48-hour treatment with various concentrations of idebenone (black curve, diamonds) and additionally treated with $600 \mu \mathrm{M}$ hydrogen peroxide $\left(\mathrm{H}_{2} \mathrm{O}_{2}\right)$ (gray curve, squares), measured by a colorimetric test (MTT). Error bars, SD. *Significant difference between the 2 curves.

\section{SA $\beta$-Gal Activity}

Idebenone $(10 \mu \mathrm{M})$ had no significant effect on SA $\beta$ Gal activity in ONHA. In contrast, addition of $600 \mu \mathrm{M}$ $\mathrm{H}_{2} \mathrm{O}_{2}$, significantly increased SA $\beta$-Gal activity. A significantly reduced SA $\beta$-Gal activity was noted when cells were pretreated with $10 \mu \mathrm{M}$ idebenone and then exposed to $600 \mu \mathrm{M} \mathrm{H}_{2} \mathrm{O}_{2}$ (Fig. 3A, upper row, and Fig. 3B).

\section{Intracellular ROS}

In untreated ONHA only a faint CM-H2DCFDA staining of ONHA was detected. After treatment of ONHA with $10 \mu \mathrm{M}$ idebenone no significant increase in CMH2DCFDA staining could be detected, whereas after treatment with $600 \mu \mathrm{M} \mathrm{H}_{2} \mathrm{O}_{2} \mathrm{CM}-\mathrm{H} 2 \mathrm{DCFDA}$ staining was markedly increased (Fig. 3A, lower row). When ONHA were pretreated with $10 \mu \mathrm{M}$ idebenone and then treated with $600 \mu \mathrm{M} \mathrm{H}_{2} \mathrm{O}_{2}$, CM-H2DCFDA staining was noted, but it was markedly less pronounced compared with cells that were treated with $600 \mu \mathrm{M} \mathrm{H}_{2} \mathrm{O}_{2}$ alone (Fig. 3A, lower row).

\section{Detection of Histone-associated DNA Fragments in Mononucleosomes and Oligonucleosomes}

To investigate the putative effects of idebenone on $\mathrm{H}_{2} \mathrm{O}_{2}$-induced apoptosis in ONHA, detection of histoneassociated DNA fragments in mononucleosomes and oligonucleosomes was conducted using the ELISA method. In our experimental set-up, exposure to $600 \mu \mathrm{M} \mathrm{H}_{2} \mathrm{O}_{2}$ led to a significant increase of histone-associated DNA fragments in cultured ONHA. In contrast, when cells were pretreated with idebenone and then exposed to $600 \mu \mathrm{M} \mathrm{H}_{2} \mathrm{O}_{2}$, idebenone treatment decreased the amount of histone-associated DNA fragments significantly, compared with those cells that were not pretreated with idebenone (Fig. 4).

\section{Expression of $\mathrm{BCl}-2$ and $\mathrm{BAX}$ mRNA in ONHA}

BAX and Bcl-2 mRNA expression was detected in every sample. All detected mRNA levels of BAX and Bcl-2 were normalized to those of $18 \mathrm{~S}$ rRNA; the values are expressed as the relative ratio of $\mathrm{Bcl}-2 / 18 \mathrm{~S}$ or $\mathrm{BAX} / 18 \mathrm{~S}$. Treatment with $\mathrm{H}_{2} \mathrm{O}_{2}$ led to a significant decrease in Bcl-2 mRNA expression in ONHA, but this decrease of $\mathrm{Bcl}-2$ mRNA expression after exposure to oxidative stress was significantly reduced when cells were pretreated with idebenone (Fig. 5). In contrast, expression of BAX mRNA was increased in ONHA after $\mathrm{H}_{2} \mathrm{O}_{2}$ treatment, and pretreatment of ONHA with idebenone significantly reduced this $\mathrm{H}_{2} \mathrm{O}_{2}$-induced increase in BAX (Fig. 5).

\section{Protein Expression of $\mathrm{Bcl}-2$ and $\mathrm{BAX}$ in ONHA}

After $\mathrm{H}_{2} \mathrm{O}_{2}$ exposure, a marked decrease in Bcl-2 expression could be detected compared with those cells that were not treated with $\mathrm{H}_{2} \mathrm{O}_{2}$. This decrease was reduced when cells were pretreated with $10 \mu \mathrm{M}$ idebenone (Fig. 6). In contrast, BAX expression was increased compared with the control when cells were exposed to oxidative stress without idebenone pretreatment. Pretreatment with idebenone attenuated this $\mathrm{H}_{2} \mathrm{O}_{2}$-mediated stimulation of $\mathrm{BAX}$ protein synthesis (Fig. 6).

\section{DISCUSSION}

A number of hypotheses have been proposed and continue to be investigated to explain the mechanisms of glaucomatous damage. To date, reduction of IOP is the only method proven to be effective in preventing or 
A

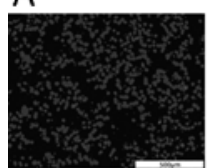

Co
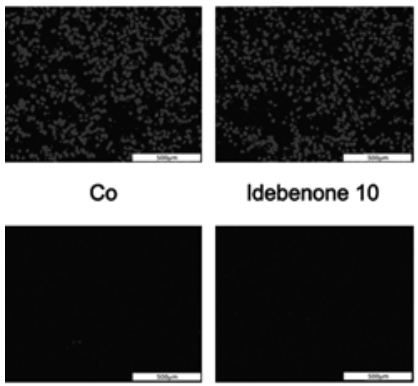

Idebenone 10
Hoechst 33342

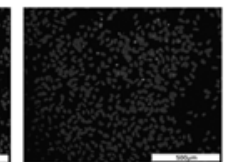

Idebenone 100

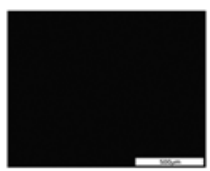

propidium iodide

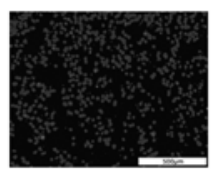

$\mathrm{H}_{2} \mathrm{O}_{2}$
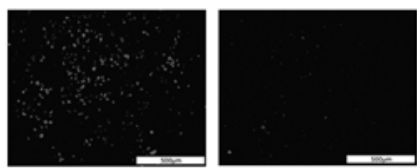

Idebenone $10+\mathrm{H}_{2} \mathrm{O}_{2}$
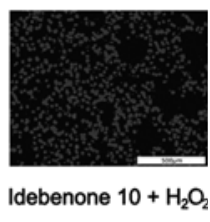

B

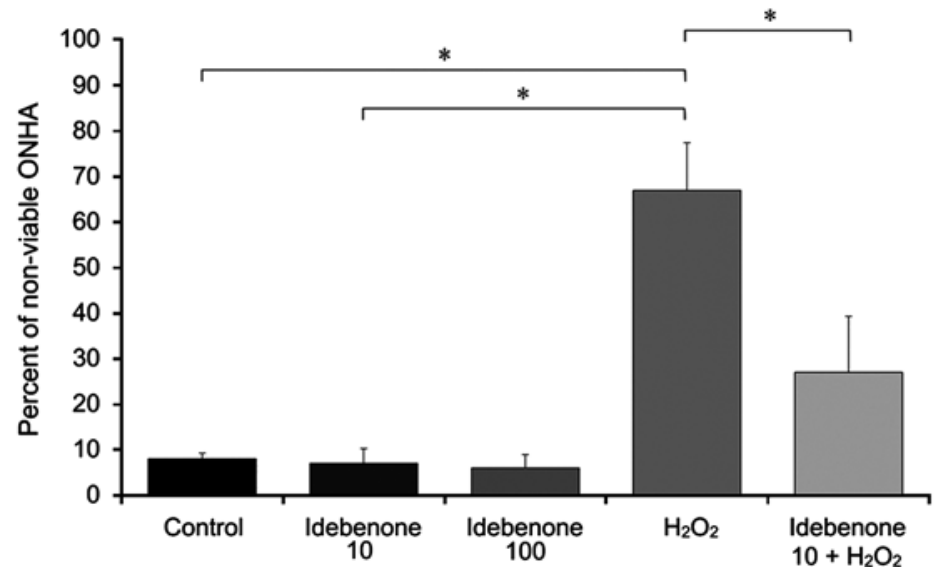

FIGURE 2. ONHA were treated for $48 \mathrm{~h}$ with various concentrations of idebenone only or with 10 and $100 \mu \mathrm{g} / \mathrm{mL}$ of idebenone (Idebenone 10 and 100) for $48 \mathrm{~h}$ and $600 \mu \mathrm{M} \mathrm{H}_{2} \mathrm{O}_{2}$ for $4 \mathrm{~h}$ as described. After exposure of the cells to idebenone alone or in combination with oxidative stress, viability was determined by staining all nuclei with Hoechst 33342 and dead cells with propidium iodide. A, Control: Representative fluorescence photomicrograph of Hoechst 33342-stained, untreated ONHA as the control and nonviable cells in the corresponding field. Idebenone 10 and 100: Fluorescence photomicrograph of ONHA treated with $10 \mu \mathrm{M}$ or $100 \mu \mathrm{M}$ idebenone for $48 \mathrm{~h}$, labeled with Hoechst 33342, and nonviable ONHA treated with $10 \mu \mathrm{M}$ for $48 \mathrm{~h}$ in the same field. $\mathrm{H}_{2} \mathrm{O}_{2}$ : Fluorescence photomicrograph of ONHA treated with $600 \mu \mathrm{M} \mathrm{H}_{2} \mathrm{O}_{2}$ only and nonviable ONHA treated with $600 \mu \mathrm{M} \mathrm{H}_{2} \mathrm{O}_{2}$ only in the same field. $\mathrm{H}_{2} \mathrm{O}_{2}+$ Idebenone $10+\mathrm{H}_{2} \mathrm{O}_{2}$ : Fluorescence photomicrograph of ONHA treated with idebenone concentrations of $10 \mu \mathrm{M}$ for $48 \mathrm{~h}$ and with $600 \mu \mathrm{M} \mathrm{H}_{2} \mathrm{O}_{2}$, labeled with Hoechst 33342, and nonviable ONHA treated with idebenone concentrations of $10 \mu \mathrm{M}$ for $48 \mathrm{~h}$ and with $600 \mu \mathrm{M} \mathrm{H} \mathrm{O}_{2}$ in the same field; scale bar: $500 \mu \mathrm{m}$. B, statistical evaluation of "A"; $* P<0.001$.

delaying progression of glaucomatous damage. However, given that oxidative stress is associated with degeneration of neuronal tissue in glaucoma, this process may provide novel targets for developing new treatments. ${ }^{2-14}$

In this study, exposure of primary human ONHA to exogenous oxidative stress not only led to an increase of SA $\beta-G a l$, a specific protein marker for cellular aging processes, but also an increase of intracellular ROS. Increased generation of ROS in the optic nerve head and retina has been demonstrated in experimental animal models of glaucoma and moderate chronic elevated IOP. Besides, an increase of intracellular ROS is commonly found in glaucomatous neurodegeneration. ${ }^{25,26,44}$ ROS are partially reduced, highly reactive metabolites derived from one-electron reduction reactions with oxygen and are mainly generated via the electron transport chain. An increase in ROS intermediates and oxidative stress is considered to induce apoptotic cell death and has been implicated in the progression of aging. ${ }^{45,46}$

Mitochondria are ubiquitous in all cells and play an important role in energy (ATP) production through the oxidative phosphorylation pathway. They are the major site of ROS production and play a central role in both extrinsic and intrinsic apoptotic pathways. In chronic glaucoma, apoptosis can be found even in early stages of the disease. Further, mitochondrial dysfunction of both neuronal and glial cells ${ }^{43}$ seems to play a key role in the predisposition to neuronal cell death in almost every age-related disorder, including glaucoma. ${ }^{24,47}$ In fact, a variety of apoptotic stimuli can alter mitochondria permeability and potentially result in functional disorder, including the release of proapoptotic proteins such as the BAX protein normally located in the mitochondrial intermembrane space..$^{9,48,49}$

$\mathrm{BAX}$ is one key protein within a major pathway of the cell death program. It is upregulated by the tumor suppressor protein p53 and is highly associated with apoptotic cell death. ${ }^{50-52}$ In contrast, Bcl-2 is a strong inhibitor of apoptosis and a counterpart of the BAX protein. It is generally considered to be a custodian of mitochondrial functional integrity, as it stabilizes the mitochondrial membrane against the release of cytochrome $c$. Bcl-2 is able to interrupt apoptosis through its inhibitory effect on caspase activation. ${ }^{53,54} \mathrm{An}$ imbalance in the ratio of BAX and Bcl-2 toward an excess of BAX leads to apoptotic cell death in many cellular systems. ${ }^{50-54}$ Therefore, an important result of our study is that oxidative stress not only led to an 
A

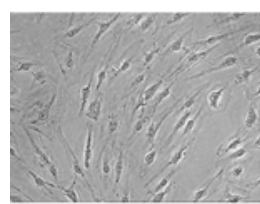

Co

B

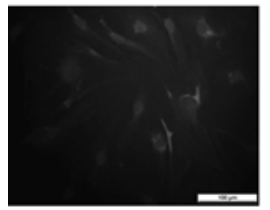

B-Galactosidase staining

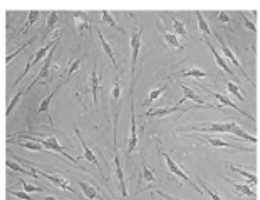

Idebenone

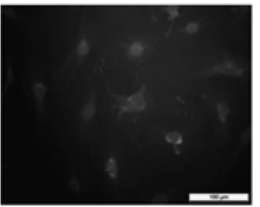

CM-H2DCFDA (detection of ROS)

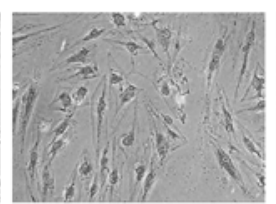

$\mathrm{H}_{2} \mathrm{O}_{2}$
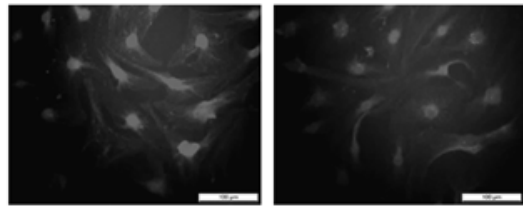

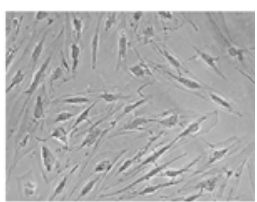

Idebenone $+\mathrm{H}_{2} \mathrm{O}_{2}$

C

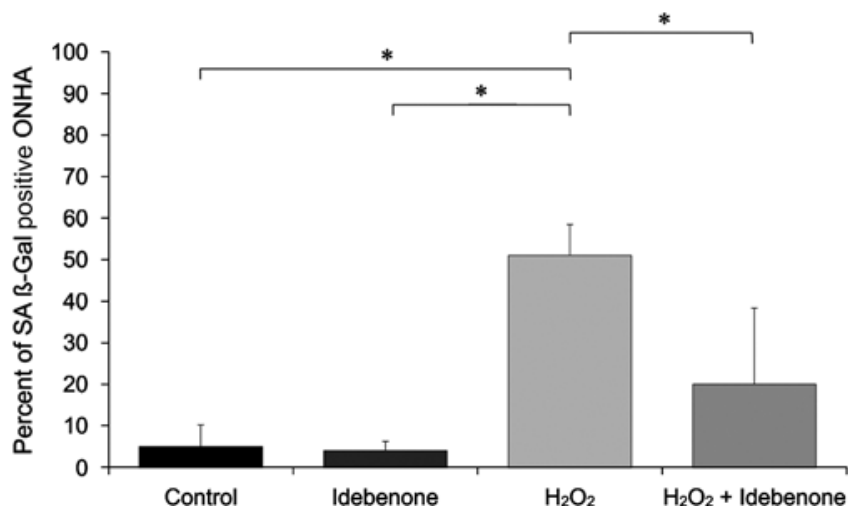

FIGURE 3. Detection of senescence-associated $\beta$-galactosidase activity is shown in A: Treatment of primary human ONHA with $10 \mu \mathrm{M}$ idebenone did not lead to significantly increased number of cells that were developing the typical color (dark grey) for $\beta$-galactosidase activity compared to the untreated control cells. When cells were treated with $600 \mu \mathrm{M} \mathrm{H}_{2} \mathrm{O}_{2}$ a significant increase in $\beta$-galactosidase staining could be detected. This increased number of $\beta$-galactosidase positive cells after $600 \mu \mathrm{M} \mathrm{H}_{2} \mathrm{O}_{2}$ treatment was significantly reduced when cells were pre-incubated with $10 \mu \mathrm{M}$ idebenone for $48 \mathrm{~h}$. B, Detection of intracellular ROS (CM-H2DCFDA): In ONHA treated with $600 \mu \mathrm{M} \mathrm{H}_{2} \mathrm{O}_{2}$ without idebenone pretreatment, an increase in intracellular ROS could be detected. This increase was reduced when ONHA were pretreated with $10 \mu \mathrm{M}$ idebenone. $\mathrm{C}$, statistical evaluation of "A"; $* P<0.001$.

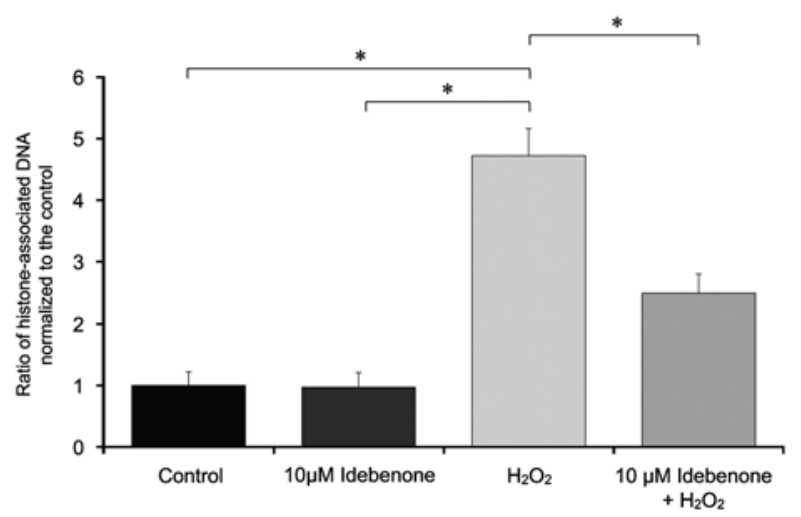

FIGURE 4. Inhibitory effect of idebenone on hydrogen peroxide $\left(\mathrm{H}_{2} \mathrm{O}_{2}\right)$-induced apoptosis in optic nerve head astrocytes (ONHA). Histone-associated DNA fragmentation in ONHA as investigated by an enzyme-linked immune sorbent assay method. Untreated control (control), ONHA treated with $600 \mu \mathrm{M} \mathrm{H} \mathrm{H}_{2} \mathrm{O}_{2}\left(\mathrm{H}_{2} \mathrm{O}_{2}\right)$, after treatment with $10 \mu \mathrm{M}$ idebenone (idebenone) only, or after idebenone treatment and additional treatment with $600 \mu \mathrm{M} \mathrm{H} \mathrm{H}_{2} \mathrm{O}_{2}$ (idebenone $+\mathrm{H}_{2} \mathrm{O}_{2}$ ). $Y$-axis: ratio of histone-associated DNA fragmentation of each probe normalized to histone-associated DNA fragmentation of the control. Data are means \pm SD. increase in apoptosis and proapoptotic BAX protein, but also to a significant decrease of the antiapoptotic Bcl-2 protein in primary human ONHA.

Idebenone is a synthetic analogue of ubiquinone, an essential constituent of the electron transport chain and a vital cell membrane antioxidant. Its benzoquinone ring can undergo reversible reduction-oxidation reactions, and similar to ubiquinone, can influence the electron balance within mitochondria. ${ }^{27}$ Idebenone interacts with the mitochondrial respiratory chain as an electron carrier from complexes I and II to complex III, providing support for mitochondrial function and ATP production. ${ }^{27}$ In addition, idebenone acts as an antioxidant, protecting membranes from damage by inhibiting lipid peroxidation in mitochondria. ${ }^{27}$ When compared with a series of structural analogues, idebenone seems to have an optimal chemical structure for the restoration of mitochondrial function. ${ }^{55}$

Because of its ability to support mitochondrial energy production and its antioxidant action, idebenone was initially evaluated for the treatment of cognitive disorders and the Alzheimer disease. ${ }^{34,56,57}$ In addition, the favorable safety profile of idebenone and its dual mechanism of action led to the investigation of its use in other neurodegenerative diseases with mitochondrial impairment. ${ }^{33,34}$ 

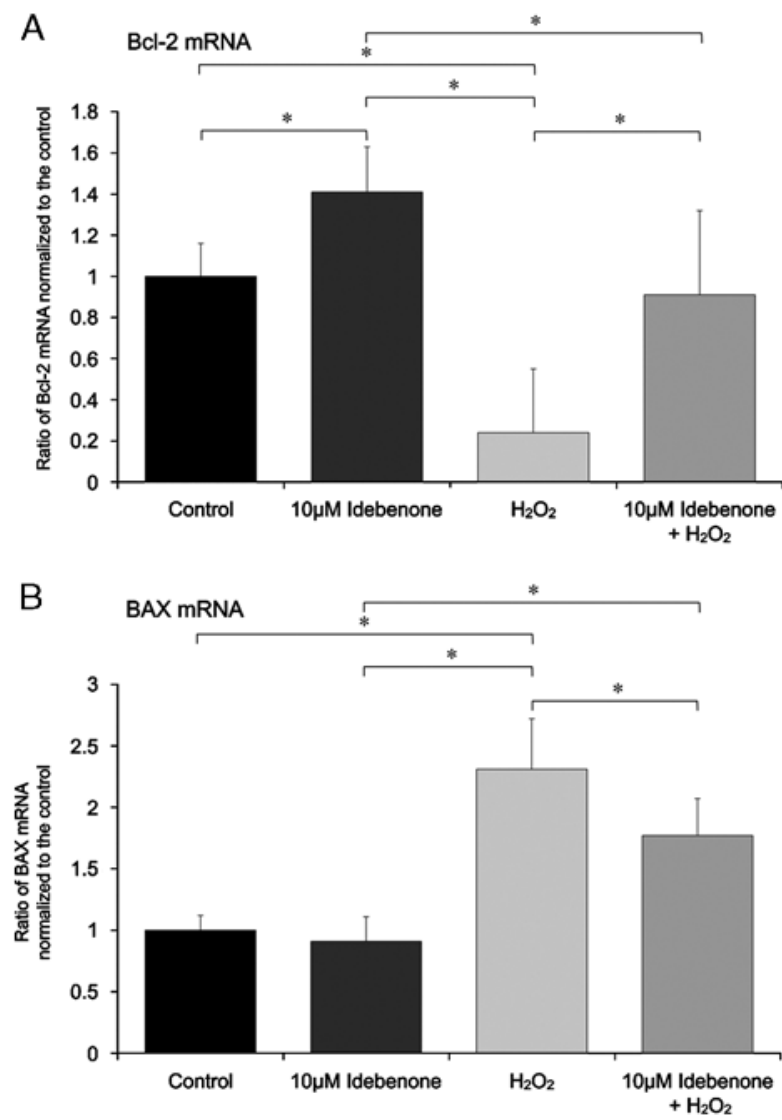

FIGURE 5. BCl-2 (A) and BAX (B) mRNA expression of ONHA after 48-h treatment with $10 \mu \mathrm{M}$ idebenone (Idebenone) only or after additional treatment with $600 \mu \mathrm{M} \mathrm{H} \mathrm{H}_{2} \mathrm{O}_{2}$ (Idebenone+ $\mathrm{H}_{2} \mathrm{O}_{2}$ ) as investigated by quantitative rt-PCR. X-axis: concentrations of idebenone tested; $\mathrm{Y}$-axis: relative ratio of $\mathrm{BAX}$ or $\mathrm{BCl}-2$ mRNA normalized to $18 \mathrm{~S}$ rRNA expressed in decimal format.

In such disease, idebenone has been shown to reduce markers of oxidative DNA damage, which are also closely related to aging processes. ${ }^{27,28}$

In our in vitro study, idebenone effectively reduced intracellular ROS in primary human ONHAs. Moreover, under the investigated experimental conditions of oxidative stress, idebenone treatment reduced the $\mathrm{H}_{2} \mathrm{O}_{2}$-induced decrease in metabolic activity of cells effectively. These results support the conclusion that idebenone has the capacity to reduce oxidative stress in ONHAs and potentially increase viability of these cells under conditions of oxidative stress in glaucomatous eyes. As the support cells for RGCs, this could potentially and indirectly result in increased RGC viability because of the intact support network.

Supporting these findings, another important result of our experiments is that pretreatment of ONHA with idebenone led to a significant reduction of cell death, apoptosis, and SA $\beta$-Gal after exposure to oxidative stress. Moreover, the $\mathrm{H}_{2} \mathrm{O}_{2}$-induced increase of $\mathrm{BAX}$ and decrease of Bcl-2 were significantly attenuated by idebenone.

The exact mechanisms of idebenone's action are not completely understood. We can speculate that the antiapoptotic effects of idebenone in our experimental set-up are, at least in part, derived from its antioxidant properties.

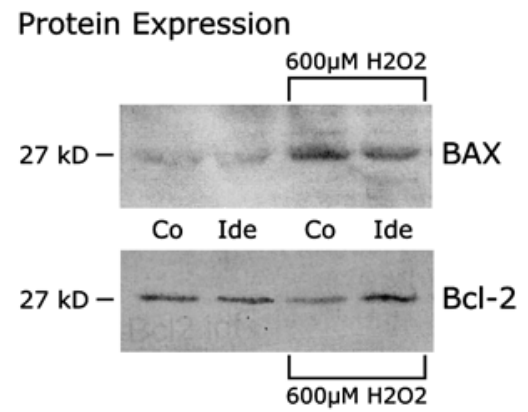

FIGURE 6. Effects of idebenone treatment on BAX and $\mathrm{BCl}-2$ protein expression. ONHA were treated with $10 \mu \mathrm{M}$ idebenone for $48 \mathrm{~h}$ only or additionally with $600 \mu \mathrm{M} \mathrm{H}_{2} \mathrm{O}_{2}$. Western blotting was used to analyze protein expression in the control (Co) and in treated cell extracts, $10 \mu \mathrm{M}$ idebenone (Ide), $600 \mu \mathrm{M} \mathrm{H}_{2} \mathrm{O}_{2}$ only, and $10 \mu \mathrm{M}$ idebenone and $600 \mu \mathrm{M} \mathrm{H}_{2} \mathrm{O}_{2}$. Ten micrograms of protein were loaded per lane. Even protein load in each lane was confirmed by Coomassie Brilliant Blue staining of the polyvinyl difluoride membranes.

In contrast, idebenone is structurally related to coenzyme Q10, which is an important component of the mitochondrial respiratory chain directly involved in mitochondrial electron transport. ${ }^{33}$ Therefore, idebenone likely has a direct impact on the intrinsic apoptotic pathway. ${ }^{33,34,58}$

In conclusion, the data of this in vitro study indicate that the properties of idebenone allow it to potentially prevent ONHA death and aging due to oxidative damage in vivo. Idebenone is a safe and well-tolerated drug. Therefore, idebenone supplementation might be a feasible and promising way to prevent the progression of glaucomatous neurodegeneration by sustaining the viability of ONHA that assist in maintaining the health of RGC. Further experimental and preclinical studies will be needed to substantiate our in vitro findings and define the potential role of idebenone in the context of clinical glaucoma treatment.

\section{ACKNOWLEDGMENT}

The authors thank Katja Obholzer for excellent technical assistance.

\section{REFERENCES}

1. Quigley HA, Broman AT. The number of people with glaucoma worldwide in 2010 and 2020. Br J Ophthalmol. 2006; 90:262-267.

2. Kass MA, Heuer DK, Higginbotham EJ, et al. The Ocular Hypertension Treatment Study: a randomized trial determines that topical ocular hypotensive medication delays or prevents the onset of primary open-angle glaucoma. Arch Ophthalmol. 2002;120:701-713; discussion 829-830.

3. Heijl A, Leske MC, Bengtsson B, et al. Reduction of intraocular pressure and glaucoma progression: results from the Early Manifest Glaucoma Trial. Arch Ophthalmol. 2002;120:1268-1279.

4. Leske MC, Heijl A, Hussein M, et al. Factors for glaucoma progression and the effect of treatment: the early manifest glaucoma trial. Arch Ophthalmol. 2003;121:48-56.

5. Leske MC, Heijl A, Hyman L, et al. Predictors of long-term progression in the early manifest glaucoma trial. Ophthalmology. 2007;114:1965-1972. 
6. Kerrigan LA, Zack DJ, Quigley HA, et al. TUNEL-positive ganglion cells in human primary open-angle glaucoma. Arch Ophthalmol. 1997;115:1031-1035.

7. Libby RT, Li Y, Savinova OV, et al. Susceptibility to neurodegeneration in a glaucoma is modified by Bax gene dosage. PLoS Genet. 2005;1:17-26.

8. Tatton NA, Tezel G, Insolia SA, et al. In situ detection of apoptosis in normal pressure glaucoma. A preliminary examination. Surv Ophthalmol. 2001;45(suppl 3):S268-S272; discussion S73-S76.

9. Tatton WG, Chalmers-Redman RM, Tatton NA. Apoptosis and anti-apoptosis signalling in glaucomatous retinopathy. Eur J Ophthalmol. 2001;11(suppl 2):S12-S22.

10. Kernt M, Neubauer AS, Ulbig MW, et al. In vitro safety of intravitreal moxifloxacin for endophthalmitis treatment. $J$ Cataract Refract Surg. 2008;34:480-488.

11. Kernt M, Liegl RG, Rueping J, et al. Sorafenib protects human optic nerve head astrocytes from light-induced overexpression of vascular endothelial growth factor, plateletderived growth factor, and placenta growth factor. Growth Factors. 2010;28:211-220.

12. Kernt M, Kampik A. Intraocular caspofungin: in vitro safety profile for human ocular cells. Mycoses. 2011;54:110-121.

13. Prasanna G, Krishnamoorthy R, Yorio T. Endothelin astrocytes and glaucoma. Exp Eye Res. 2011;93:170-177.

14. Hernandez MR, Miao H, Lukas T. Astrocytes in glaucomatous optic neuropathy. Prog Brain Res. 2008;173:353-373.

15. Luo C, Yang X, Kain AD, et al. Glaucomatous tissue stress and the regulation of immune response through glial Toll-like receptor signaling. Invest Ophthalmol Vis Sci. 2010;51: 5697-5707.

16. Johnson EC, Morrison JC. Friend or foe? Resolving the impact of glial responses in glaucoma. J Glaucoma. 2009;18: 341-353.

17. Ganesh BS, Chintala SK. Inhibition of reactive gliosis attenuates excitotoxicity-mediated death of retinal ganglion cells. PLoS One. 2011;6:e18305.

18. Galpern WR, Cudkowicz ME. Coenzyme Q treatment of neurodegenerative diseases of aging. Mitochondrion. 2007; 7(suppl):S146-S153.

19. Imagawa M, Naruse S, Tsuji S, et al. Coenzyme Q10, iron, and vitamin B6 in genetically-confirmed Alzheimer's disease. Lancet. 1992;340:671.

20. Ferreira SM, Lerner SF, Brunzini R, et al. Oxidative stress markers in aqueous humor of glaucoma patients. $\mathrm{Am} J$ Ophthalmol. 2004;137:62-69.

21. Levin LA, Clark JA, Johns LK. Effect of lipid peroxidation inhibition on retinal ganglion cell death. Invest Ophthalmol Vis Sci. 1996;37:2744-2749.

22. Sacca SC, Pascotto A, Camicione P, et al. Oxidative DNA damage in the human trabecular meshwork: clinical correlation in patients with primary open-angle glaucoma. Arch Ophthalmol. 2005;123:458-463.

23. Hollyfield JG, Bonilha VL, Rayborn ME, et al. Oxidative damage-induced inflammation initiates age-related macular degeneration. Nat Med. 2008;14:194-198.

24. Kong GY, Van Bergen NJ, Trounce IA, et al. Mitochondrial dysfunction and glaucoma. J Glaucoma. 2009;18:93-100.

25. Kumar DM, Agarwal N. Oxidative stress in glaucoma: a burden of evidence. J Glaucoma. 2007;16:334-343.

26. Liu Q, Ju WK, Crowston JG, et al. Oxidative stress is an early event in hydrostatic pressure induced retinal ganglion cell damage. Invest Ophthalmol Vis Sci. 2007;48:4580-4589.

27. McDaniel DH, Neudecker BA, DiNardo JC, et al. Idebenone: a new antioxidant-part I. Relative assessment of oxidative stress protection capacity compared to commonly known antioxidants. $J$ Cosmet Dermatol. 2005;4:10-17.

28. Meier T, Buyse G. Idebenone: an emerging therapy for Friedreich ataxia. $J$ Neurol. 2009;256(suppl 1):25-30.

29. Mestre T, Ferreira J, Coelho MM, et al. Therapeutic interventions for disease progression in Huntington's disease. Cochrane Database Syst Rev. 2009;3:CD006455.
30. Voronkova KV, Meleshkov MN. Use of Noben (idebenone) in the treatment of dementia and memory impairments without dementia. Neurosci Behav Physiol. 2009;39:501-506.

31. Klopstock T, Yu-Wai-Man P, Dimitriadis $\mathrm{K}$, et al. A randomized placebo-controlled trial of idebenone in Leber's hereditary optic neuropathy. Brain. 2011;134(pt 9): 2677-2686.

32. Neufeld AH, Liu B. Glaucomatous optic neuropathy: when glia misbehave. Neuroscientist. 2003;9:485-495.

33. Villalba JM, Parrado C, Santos-Gonzalez M, et al. Therapeutic use of coenzyme Q10 and coenzyme Q10-related compounds and formulations. Expert Opin Investig Drugs. 2010;19: 535-554.

34. Deigner HP, Haberkorn U, Kinscherf R. Apoptosis modulators in the therapy of neurodegenerative diseases. Expert Opin Investig Drugs. 2000;9:747-764.

35. Gil J, Almeida S, Oliveira CR, et al. Cytosolic and mitochondrial ROS in staurosporine-induced retinal cell apoptosis. Free Radic Biol Med. 2003;35:1500-1514.

36. Kernt M, Neubauer AS, Eibl KH, et al. Minocycline is cytoprotective in human trabecular meshwork cells and optic nerve head astrocytes by increasing expression of XIAP, survivin, and Bcl-2. Clin Ophthalmol. 2010;4:591-604.

37. Mosmann T. Rapid colorimetric assay for cellular growth and survival: application to proliferation and cytotoxicity assays. J Immunol Methods. 1983;65:55-63.

38. Kernt M, Neubauer AS, Liegl RG, et al. Sorafenib prevents human retinal pigment epithelium cells from light-induced overexpression of VEGF, PDGF and PIGF. Br J Ophthalmol. 2010;94:1533-1539.

39. Kernt M, Hirneiss C, Neubauer AS, et al. Coenzyme Q10 prevents human lens epithelial cells from light-induced apoptotic cell death by reducing oxidative stress and stabilizing BAX/Bcl-2 ratio. Acta Ophthalmol. 2010;88:e78-e86.

40. Dimri GP, Lee X, Basile G, et al. A biomarker that identifies senescent human cells in culture and in aging skin in vivo. Proc Natl Acad Sci USA. 1995;92:9363-9367.

41. Nishikawa T, Edelstein D, Du XL, et al. Normalizing mitochondrial superoxide production blocks three pathways of hyperglycaemic damage. Nature. 2000;404:787-790.

42. Kernt M, Hirneiss $\mathrm{C}$, Wolf $\mathrm{A}$, et al. Indocyanine green increases light-induced oxidative stress, senescence, and matrix metalloproteinases 1 and 3 in human RPE cells. Acta Ophthalmol. 2012;90:571-579.

43. Kernt M, Neubauer AS, Liegl R, et al. Cytoprotective effects of a blue light-filtering intraocular lens on human retinal pigment epithelium by reducing phototoxic effects on vascular endothelial growth factor-alpha, Bax, and Bcl-2 expression. $J$ Cataract Refract Surg. 2009;35:354-362.

44. Moreno MC, Campanelli J, Sande P, et al. Retinal oxidative stress induced by high intraocular pressure. Free Radic Biol Med. 2004;37:803-812.

45. Temple MD, Perrone GG, Dawes IW. Complex cellular responses to reactive oxygen species. Trends Cell Biol. 2005; 15:319-326.

46. Canakci CF, Cicek Y, Canakci V. Reactive oxygen species and human inflammatory periodontal diseases. Biochemistry (Mosc). 2005;70:619-628.

47. Jarrett SG, Lin H, Godley BF, et al. Mitochondrial DNA damage and its potential role in retinal degeneration. Prog Retin Eye Res. 2008;27:596-607.

48. Zamzami N, Kroemer G. The mitochondrion in apoptosis: how Pandora's box opens. Nat Rev Mol Cell Biol. 2001;2: $67-71$.

49. Martinou JC, Green DR. Breaking the mitochondrial barrier. Nat Rev Mol Cell Biol. 2001;2:63-67.

50. Chang MY, Sun W, Ochiai W, et al. Bcl-XL/Bax proteins direct the fate of embryonic cortical precursor cells. Mol Cell Biol. 2007;27:4293-4305.

51. Liang YG, Jorgensen AG, Kaestel CG, et al. Bcl-2, Bax, and c-Fos expression correlates to RPE cell apoptosis induced by UV-light and daunorubicin. Curr Eye Res. 2000;20:25-34. 
52. Lindsten T, Zong WX, Thompson CB. Defining the role of the Bcl-2 family of proteins in the nervous system. Neuroscientist. 2005; 11:10-15.

53. Kluck RM, Esposti MD, Perkins G, et al. The pro-apoptotic proteins, Bid and Bax, cause a limited permeabilization of the mitochondrial outer membrane that is enhanced by cytosol. J Cell Biol. 1999;147:809-822.

54. Esposti MD, Hatzinisiriou I, McLennan H, et al. Bcl-2 and mitochondrial oxygen radicals. New approaches with reactive oxygen species-sensitive probes. J Biol Chem. 1999;274: 29831-29837.

55. Okamoto K, Matsumoto M, Watanabe M, et al. Effects of 6-(omega-substituted alkyl)-2,3-dimethoxy-5-methyl-1,4-ben- zoquinones and related compounds on mitochondrial succinate and reduced nicotinamide adenine dinucleotide oxidase systems. Chem Pharm Bull (Tokyo). 1985;33: 3745-3755.

56. Bergamasco B, Scarzella L, La Commare P. Idebenone, a new drug in the treatment of cognitive impairment in patients with dementia of the Alzheimer type. Funct Neurol. 1994;9: $161-168$.

57. Sramek JJ, Cutler NR. Recent developments in the drug treatment of Alzheimer's disease. Drugs Aging. 1999;14: 359-373.

58. Crane FL. Biochemical functions of coenzyme Q10. J Am Coll Nutr. 2001;20:591-598. 